\title{
An evaluation of the NR-1000F Auto Refractometer in high refractive errors
}

\author{
BARUN KUMAR NAYAK, SUPRIYO GHOSE, "AND JAI PAL SINGH
}

From the Dr Rajendra Prasad Centre for Ophthalmic Sciences, All India Institute of Medical Sciences, Ansari Nagar, New Delhi - 110 029, India

SUMmaRY The manifest refractions of 37 high myopic and 16 high hypermetropic eyes in a total of 28 patients, aged 5 to 42 years, were determined on the Nikon NR-1000F Auto Refractometer. The data obtained were compared with the final clinical prescriptions for these eyes and analysed for degree of agreement for the spherical equivalents, sphere components, and cylinder powers and axes. The Auto Refractometer recordings for all the different refractive components were observed to skew towards more minus in the high myopic eyes but more plus in the high hypermetropes. The possible significance of these skewing patterns is discussed with reference to our earlier studies.

In an earlier study ${ }^{1}$ on the Nikon NR-1000F Auto Refractometer (AR) we had carried out a systematic evaluation of the manifest (dry) refractions of 165 eyes with various types of refractive errors over a wide range of ages. A comparison of the AR readings with their corresponding manifest clinical refractive data had shown all the refractive components (spherical equivalent, sphere, and cylinder components) to skew strongly towards more minus (or less plus) on the AR. This error in manifest AR readings was greater in emmetropes, low hypermetropes, and low myopes. The skewing declined with increasing age over 40 years and was also significantly lower in aphakia and mixed

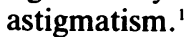

Further comparative studies between $\mathrm{AR}$ and clinical refractions were undertaken, both under manifest and cycloplegic conditions, in younger patients with low refractive errors. ${ }^{2}$ This analysis substantiated our earlier suspicions that, in spite of the inbuilt automatic fogging system, the fixation target in the NR-1000F induces significant instrument myopia during manifest refractions in these patients. ${ }^{2}$

A definite difference had been observed in the skewing patterns on the manifest AR between eyes

Correspondence to Dr Supriyo Ghose, Dr Rajendra Prasad Centre for Ophthalmic Sciences, All India Institute of Medical Sciences, Ansari Nagar, New Delhi - 110 029, India. with lower and higher refractive errors, though admittedly the number of eyes in the latter group was very few indeed. ${ }^{\prime}$ In this paper we shall present our further experiences on the AR in eyes with high refractive error and discuss their significance in the context of our earlier studies.

\section{Materials and methods}

A total of 53 eyes in 28 patients were examined. The patients' ages ranged from 5 to 42 years (Table 1 ); 17 were males. None of the patients were paramedical or medical staff, and no patient was familiar with the Auto Refractometer. Only cases of myopia of more than $-6 \mathrm{D}$ and hypermetropia of more than $+6 \mathrm{D}$ were selected for this analysis.

All refractions on the AR were performed without the effect of any mydriatics or cycloplegics. The clinical refractions were either done similarly (manifest or dry), or if necessary under the effect of cycloplegics (homatropine $2 \%$ drops or atropine $1 \%$ ointment) or mydriatics (phenylephrine $10 \%$ drops), depending upon the age of the patient, in accordance with the guidelines routinely followed in clinical refractive practice. The final prescriptions to the patient were based on the objective clinical refraction data and the subjective acceptance, and these final prescriptions were then compared with the manifest AR printout data. 
Table 1 Distribution by age of 28 patients with high refractive errors

\begin{tabular}{lll}
\hline Age groups (years) & \multicolumn{2}{c}{ Type of refractive error } \\
\cline { 2 - 3 } & Ho. of patients) \\
\cline { 2 - 3 } & High myopia & $\begin{array}{l}\text { High } \\
\text { hypermetropia }\end{array}$ \\
\hline$<10$ & 2 & 1 \\
$11-20$ & 12 & 2 \\
$21-30$ & 4 & 1 \\
$31-40$ & 1 & 4 \\
$41-50$ & 0 & 1 \\
Total & 19 & 9 \\
\hline
\end{tabular}

Table 2 Mean differences and standard deviations between Auto Refractometer and clinical refractive data in 53 eyes with high refractive errors

\begin{tabular}{|c|c|c|c|c|c|}
\hline & & $\begin{array}{l}\text { Spherical } \\
\text { equivalent } \\
\text { (D) }\end{array}$ & $\begin{array}{l}\text { Sphere } \\
\text { component } \\
\text { (D) }\end{array}$ & $\begin{array}{l}\text { Cylinder } \\
\text { component } \\
\text { (D) }\end{array}$ & $\begin{array}{l}\text { Cylinder } \\
\text { axis }\left({ }^{\circ}\right)\end{array}$ \\
\hline $\begin{array}{l}\text { Myopia } \\
\text { (37 eyes) }\end{array}$ & $\begin{array}{l}\text { Mean* } \\
\text { SD }\end{array}$ & $\begin{array}{l}-0.53 \\
\pm 0.52\end{array}$ & $\begin{array}{l}-0.29 \\
\pm 0.52\end{array}$ & $\begin{array}{l}-0.52 \\
\pm 0.49\end{array}$ & $\begin{array}{r}4.42 \\
\pm 3.53\end{array}$ \\
\hline $\begin{array}{l}\text { Hypermetropia } \\
\text { (16 eyes) }\end{array}$ & $\begin{array}{l}\text { Mean* } \\
\text { SD }\end{array}$ & $\begin{array}{l}+0.34 \\
\pm 0.38\end{array}$ & $\begin{array}{l}+0 \cdot 29 \\
\pm 0.39\end{array}$ & $\begin{array}{l}+0 \cdot 12 \\
\pm 0.20\end{array}$ & $\begin{array}{r}3 \cdot 29 \\
\pm 2 \cdot 16\end{array}$ \\
\hline
\end{tabular}

*The + and - signs indicate more hypermetropia and more myopia respectively on NR-1000F than clinical refraction data.

The clinical refraction and testing on the AR were not necessarily conducted by the same person. If both the examinations were carried out by the same person the clinical refraction was invariably done first, so as to obviate any possible examiner bias in the clinical refractive data.

The principles and steps of operation of the NR$1000 \mathrm{~F}$ have been outlined earlier. ' Further information on operating and maintenance is detailed in the manufacturer's instruction manual. A minimum of three AR readings was obtained for each eye tested. In accordance with the operating manual instructions, readings with a confidence value of less than 90 were rejected. The reading with the maximum confidence value in each eye tested was selected for comparison with the clinical data.

\section{Results}

The mean difference and standard deviation between Auto Refractometer and clinical refractive readings for the various refractive components were evaluated separately for high myopia and high hypermetropia (Table 2).

The percentage agreements between $A R$ and clinical data for these refractive components (spherical equivalent, sphere component, and cylinder powers and axes) were again analysed separately for myopic and hypermetropic eyes (Table $3)$.

\section{Discussion}

Much literature has accumulated on various types of subjective and objective autorefractometers. ${ }^{3-9}$ In view of conflicting claims to accuracy we had earlier carried out a wider study on the sophisticated Nikon NR-1000F Auto Refractometer, under both manifest and cycloplegic conditions. ${ }^{12}$

In our previous study on manifest refraction' the AR recordings skewed strongly towards more minus (or less plus), especially in the emmetropic, low myopic, and low hypermetropic eyes, more so below the age of 40 years. In contrast to this, a gentle skewing towards more plus (or less minus) was observed in the few cases of aphakia, mixed astigmatism, moderate and high hypermetropia, and in general all eyes in patients over 50 years of age.

In our present study the high myopic eyes still showed a consistent skewing towards more minus on the AR, though slightly lesser than the degree of skewing observed earlier in emmetropic, low myopic, and low hypermetropic eyes. On the other hand the high hypermetropic eyes showed an equally consistent skewing towards more plus on the manifest AR. We could not detect any significant variation for the different age groups in these skewing patterns in either the myopic or hypermetropic eyes studied, though admittedly all the myopes except one were less than 22 years old, and six out of the nine hypermetropes were over 25 .

Table 3 Percentage agreement between Auto Refractometer and clinical refractive data of the various refractive components in 53 eyes with high refractive errors

\begin{tabular}{|c|c|c|c|c|c|c|c|c|c|c|c|}
\hline & \multicolumn{3}{|c|}{ Spherical equivalent (D) } & \multicolumn{3}{|c|}{ Sphere component (D) } & \multicolumn{3}{|c|}{ Cylinder component (D) } & \multicolumn{2}{|c|}{ Cylinder axis* } \\
\hline & $\pm 0 \cdot 25$ & $\pm 0 \cdot 5$ & $\pm 1 \cdot 0$ & $\pm 0 \cdot 25$ & $\pm 0 \cdot 5$ & $\pm 1 \cdot 0$ & $\pm 0 \cdot 25$ & \pm 0.5 & $\pm 1 \cdot 0$ & Within $5^{\circ}$ & Within $10^{\circ}$ \\
\hline \multirow{2}{*}{$\begin{array}{l}\text { Myopia (37 eyes) } \\
\text { Hypermetropia } \\
\text { (16 eyes) }\end{array}$} & $37 \cdot 8 \%$ & $62 \cdot 2 \%$ & $83 \cdot 8 \%$ & $54 \cdot 1 \%$ & $83 \cdot 8 \%$ & $91.9 \%$ & $32 \cdot 4 \%$ & $64.9 \%$ & $89 \cdot 2 \%$ & $37 \cdot 8 \%$ & $51 \cdot 4 \%$ \\
\hline & $37 \cdot 5 \%$ & $87 \cdot 5 \%$ & $93 \cdot 8 \%$ & $62 \cdot 5 \%$ & $87 \cdot 5 \%$ & $93 \cdot 8 \%$ & $68 \cdot 8 \%$ & $93 \cdot 8 \%$ & $100 \%$ & $62.5 \%$ & $87.5 \%$ \\
\hline
\end{tabular}

*No cylinder was detected in one of the testings in 16 of the 37 myopic eyes and in two of the 16 hypermetropic eyes. 
As eyes with high refractive errors should tend to exhibit a relative apathy towards accommodation, we had expected a significant reduction in the induced instrument myopia on the manifest AR for these eyes. As such, we are unable satisfactorily to explain this variation of skewing patterns on the manifest $A R$ for the high myopic and high hypermetropic eyes, and this difference of the induced instrumental myopic error between them. It seems that the high myope still tends to accommodate, whereas the high hypermetropic eye truly shows a lack of accommodation, and this (as observed in aphakic eyes also') not only negates the inherent instrumental myopic error of this device but overneutralises it.

The determination of cylinder axes for these eyes on the AR proved as reliable and accurate as for all other types of refractive errors, ${ }^{12}$ more so than in a subjective autorefractometer. ${ }^{9}$

Though the manifest AR data were fairly reliable for the high hypermetropes, in view of the induced instrumental myopia on this device even for the high myopic eyes it is recommended that the AR reading should be used only as a clinical guideline in such cases, and not prescribed as such straight away, without at least carefully checking the acceptance subjectively.

\section{References}

1 Ghose S, Nayak BK, Singh JP. A critical evaluation of the NR1000F (an objective Auto Refractometer). BrJ Ophthalmol 1986; 70: 221-6.

2 Nayak BK, Ghose S, Singh JP. A comparison of cycloplegic and manifest refractions on the NR-1000F (an objective auto refractometer). BrJ Ophthalmol 1987; 71: 73-5.

3 Guyton DL. Automated refraction. Invest Ophthalmol Vis Sci 1974; 13: 814-8.

4 Drance SM, Mitchell DWA, Schulzer M. Studies of an automatic refraction machine. Can J Ophthalmol 1975; 10: 462-8.

5 Polse KA, Henton BK. An automatic objective optometer. Arch Ophthalmol 1975; 93: 225-31.

6 Dyson C. A clinical study of the autorefractor, an automatic refracting device. Can J Ophthalmol 1977; 12: 29-33.

7 Pappas CJ, Anderson DR, Briese FW. Clinical evaluation of 6600 autorefractor. Arch Ophthalmol 1978; 96: 993-6.

8 Pappas CJ, Anderson DR, Briese FW. Is the autorefractor reading closest to manifest refractions? A comparison of the patient's previous spectacles and the $\mathbf{6 6 0 0}$ autorefractor reading. Arch Ophthalmol 1978; 96: 997-8.

9 Perrigin DM, Perrigin J, Grosvenor T. A clinical evaluation of the American Optical SR III subjective refractor. Am J Optom Physiol Opt 1981; 58: 581-9.

Accepted for publication 16 September 1986. 